\title{
21-Gene recurrence score influences the chemotherapy decision for patients with breast cancer of different luminal subtypes
}

\author{
WEI WANG ${ }^{1}$, LIN LIN ${ }^{2}$, XIAOCHUN FEI ${ }^{3}$, JIN HONG ${ }^{1}$, WEIQI GAO ${ }^{1}$, SIJI ZHU $^{1}$, JIAYI WU ${ }^{1}$, OU HUANG ${ }^{1}$, \\ JIANRONG HE ${ }^{1}$, YAFEN LI ${ }^{1}$, LI ZHU ${ }^{1}$, WEIGUO CHEN ${ }^{1}$, XIAOSONG CHEN ${ }^{1}$ and KUNWEI SHEN ${ }^{1}$ \\ ${ }^{1}$ Department of Breast Surgery, Comprehensive Breast Health Center, Departments of ${ }^{2}$ Clinical Laboratory and \\ ${ }^{3}$ Pathology, Ruijin Hospital, Shanghai Jiaotong University School of Medicine, Shanghai 200025, P.R. China
}

Received January 17, 2019; Accepted July 18, 2019

DOI: 10.3892/ol.2019.10766

\begin{abstract}
Luminal subtypes and the 21-gene recurrence score (RS) are important factors in the decision-making process for adjuvant chemotherapy in patients with hormonal receptor (HR)-positive/human epidermal growth factor receptor 2 (HER2)-negative breast cancer. However, their effect on adjuvant chemotherapy decisions in the real world has not been thoroughly investigated, particularly for patients of the luminal A-like subtype with a high RS or the luminal B-like subtype with a low RS. The present study, a total of $772 \mathrm{HR}^{+} / \mathrm{HER} 2$ patients who underwent 21-gene testing, were included in a retrospective analysis. The impact of clinicopathological factors and the 21-gene RS on chemotherapy recommendation was analyzed in the whole population and for patients of different luminal subgroups. The results revealed that chemotherapy was highly recommended for patients of younger age, with larger tumor size, node involvement, higher grade, luminal B-like subtype and higher RS. A high RS was identified to be the most important impact factor for chemotherapy recommendation among all patients [odds ratio (OR), 62.54; 95\% CI, 25.58-152.92], the luminal A-like group (OR, 435.05; 95\% CI, 29.90-6331.06) and the luminal B-like group (OR, 57.20; 95\% CI, 22.42-145.96). For patients of the luminal A-like subtype with a high RS or patients of the luminal B-like subtype with low RS, the 21-gene RS was demonstrated to be the most important independent factor for chemotherapy recommendation, with an adjusted OR of 134.52 (95\% CI, 10.39-1741.89). In conclusion, luminal subtypes and the 21-gene RS were found to be associated with chemotherapy recommendation for $\mathrm{HR}^{+} / \mathrm{HER} 2^{-}$patients.
\end{abstract}

Correspondence to: Dr Xiaosong Chen or Professor Kunwei Shen, Department of Breast Surgery, Comprehensive Breast Health Center, Ruijin Hospital, Shanghai Jiaotong University School of Medicine, 197 Ruijin Second Road, Shanghai 200025, P.R. China

E-mail: chenxiaosong0156@hotmail.com

E-mail:kwshen@medmail.com.cn

Key words: breast neoplasm, luminal subtype, clinicopathological, recurrence score, chemotherapy recommendation
For patients with a discordant luminal subtype and 21-gene RS risk, the 21-gene RS score was found to be the most important factor that influences chemotherapy decision, which warrants further clinical evaluation.

\section{Introduction}

Breast cancer is the most commonly diagnosed malignant tumor among Chinese women. In 2015, the estimated incidence of breast cancer was 304,000 new cases, with 70,000 associated deaths, which accounted for $6.67 \%$ of all cases of mortality in China (1). Adjuvant chemotherapy improves survival in patients with early-stage breast cancer (2); however, it is associated with severe side effects and a negative impact on the quality of life, which may outweigh treatment benefits $(3,4)$. Therefore, personalizing treatment based on tumor biology to reduce unnecessary chemotherapy is the main method of optimizing individualized patient care (5).

The recommendation of adjuvant chemotherapy is routinely based on tumor burden (tumor size and lymph node status), tumor biological characteristics (grade and immunohistochemical markers) and patient factors (menopausal status, presence of comorbid conditions and patient preference) (6). Along with the recognition of intrinsic biological subtypes within the breast cancer spectrum, a novel approach for the classification of patients for therapeutic purposes has been adopted (7). Patients were classified into four intrinsic subtypes: Luminal A, luminal B, HER 2 enriched and Basal-like subtypes. Because of economic and technical reasons, a clinicopathological surrogate definition was widely adopted in clinical setting. For hormonal receptor $(\mathrm{HR})^{+} / \mathrm{HER}^{-}$patients, luminal A-like subtype is defined as estrogen receptor (ER)-positive, with progesterone receptor (PR) $\geq 20 \%$ and Ki-67 $<14 \%$ based on clinicopathological criteria, while other $\mathrm{HR}^{+} / \mathrm{HER} 2^{-}$patients are classified as luminal B-like subtype (7). In general, systemic therapy recommendations are based on subtype classification (7). Therefore, luminal A-like disease generally requires only endocrine therapy, whereas chemotherapy is considered for most patients with breast cancer of a luminal B-like subtype (7).

Previously, several multi-gene expression profiles have also been developed to guide adjuvant chemotherapy decision making for patients with $\mathrm{HR}^{+} / \mathrm{HER} 2-$ early-stage breast 
cancer $(8,9)$. The 21-gene recurrence score (RS) has been tested using the reverse transcription-PCR method on sections of fixed, paraffin-embedded tumor tissue, which was first reported in 2004, to quantify the likelihood of distant recurrence in tamoxifen-treated patients with node-negative, ER-positive breast cancer (10). Further validation studies demonstrated that it can predict the benefit of chemotherapy in node-negative (11) and node-positive patients (12). Additionally, the latest prospective TAILORx and West German Study Group Plan B trials have indicated the prognostic value and chemotherapeutical predictive value of $\mathrm{RS}$ in patients with $\mathrm{HR}^{+} / \mathrm{HER} 2^{-}$breast cancer $(8,9,13)$. Based on these findings, the 21 -gene RS has been recommended for use in patients with $\mathrm{HR}^{+} / \mathrm{HER} 2$-, lymph node-negative breast cancer by the National Comprehensive Cancer Network (NCCN) (14).

Utilization of the 21-gene RS can lead to a change in chemotherapy recommendation for $20-70 \%$ of cases, which has resulted in a $13-34 \%$ reduction in adjuvant chemotherapy usage (15). Results from validation studies of the 21-gene RS have indicated that RS and clinicopathological parameters, including tumor size and tumor grade, are independent prognostic factors based on multivariate cox regression analysis $(9,10,13,16-18)$. In a clinical setting, treatment decisions for a specific patient should be based on clinical and genomic risk factors. According to the results of the MINDACT clinical trial, while some patients can be classified into different risk groups using clinicopathological characteristics and genomic assays, for patients with a discordant risk of clinicopathological features and a 70-gene prognosis signature, chemotherapy has no additional benefit (19). However, to the best of our knowledge, there is a dearth of data for the 21-gene RS in this segment of patients. Therefore, it is important to find out whether the chemotherapy recommendation for patients with different luminal subtypes will be affected by the 21-gene RS.

The aim of the present study was to assess the influence of the 21-gene RS on the chemotherapy decision-making process for patients with different luminal subtypes in a real world population, particularly for patients with discordance in the luminal and 21-gene RS risk categories (luminal A-like subtype with high RS or luminal B-like subtype with low RS).

\section{Materials and methods}

Study population. The present study retrospectively reviewed data on consecutive patients with breast cancer undergoing 21-gene RS testing between January 2014 and December 2016 at Ruijin Hospital (Shanghai, China). This included a total of 772 female patients with ages ranging from 26 to 88 (mean \pm standard deviation, 57.15 \pm 12.53 ). Male patients, and patients with special subtypes (carcinomas other than invasive ductal carcinoma, including invasive lobular carcinoma, carcinoma with medullary features, metaplastic carcinoma and mucinous carcinoma), HER2-positive tumors and patients with $>3$ lymph nodes involved were excluded from the study. All medical records were retrieved from the Shanghai Jiaotong University Breast Cancer database. Performance status and comorbidities were evaluated using Charlson comorbidity index (CCI), a weighted index that takes into account patient age, and the number and seriousness of comorbid diseases (20). Patients with a higher CCI score have a worse performance status. Luminal-like subtypes were defined based on the 2013 St. Gallen Expert Consensus (21). The definition of luminal A-like tumor was as follows: ER-positive, $P R \geq 20 \%$, HER2-negative and Ki-67 <14\%. Luminal B-like tumors can be divided into two groups: Luminal B-like/HER2- and luminal B-like/HER2 ${ }^{+}$. Since HER2-positive patients were not included in the present study, luminal B-like tumors in the study were defined as ER-positive, HER2-negative and PR $<20 \%$ or $\mathrm{Ki}-67 \geq 14 \%$. Since the usage of the 21 -gene RS in lymph node-positive patients remains controversial, lymph node status was evaluated to help distinguish the influence of the 21-gene RS on chemotherapy. The study protocol was approved by the Ethic Committees of Ruijin Hospital.

Evaluation of ER, PR, HER2 and Ki-67 index status. Tumors were classified histologically according to the World Health Organization Classification of Tumors guidelines (22). Tumor staging was assessed according to American Joint Committee on Cancer (AJCC) Cancer Staging Handbook (23). Histological grade was evaluated according to Elston and Ellis scoring system (24). The pathology and immunohistochemistry (IHC) staining methods used in the present study were previously described (25). Briefly, IHC staining was performed on $4 \mu \mathrm{m}$ slices of formalin-fixed paraffin-embedded (FFPE) tissue sections. Following dewaxing and antigen retrieval, the tissue sections were incubated with the peroxidase-blocking solution (ready-to-use, cat. no. S2023; Dako; Agilent Technologies, Inc.) for $10 \mathrm{~min}$ at room temperature. IHC staining of ER, PR, HER 2 and Ki-67 was routinely carried out by using the Ventana BenchMark XT system (Ventana Medical Systems, Inc.). All procedures were performed automatically in the BenchMark. The following antibodies were used for the IHC assay: ER (cat. no. IR657, clone 1D5; 1:100; mouse monoclonal; Dako; Agilent Technologies, Inc.), PR (cat. no. IR068, clone PR636, mouse monoclonal; 1:100; Dako; Agilent Technologies, Inc.), HER2 (cat. no. 790-2991, clone 4B5, rabbit monoclonal; 1:100; Roche Diagnostics) and Ki-67 (cat. no. IR626, clone MIB-1, mouse monoclonal; 1:100; Dako; Agilent Technologies, Inc.). The tissue sections were incubated with primary antibody of ER, PR and Ki67 for $32 \mathrm{~min}$ at $42^{\circ} \mathrm{C}$ and of HER2 for $16 \mathrm{~min}$ at $42^{\circ} \mathrm{C}$. Sections were incubated in secondary goat anti-mouse (cat. no. P0447; 1:100; Dako; Agilent Technologies, Inc.) or goat anti-rabbit (cat. no. P0448; 1:100; Dako; Agilent Technologies, Inc.) antibodies for $30 \mathrm{~min}$ at room temperature. All histological and IHC tumor slides were evaluated by two pathologists with a light microscope at magnification of $\mathrm{x} 100$. Positive staining for ER/PR was defined as nuclear staining in $\geq 1 \%$ of the tumor cells. The Ki-67 index was characterized as the proportion of cells with positive nuclear staining among $\geq 1,000$ tumor cells in the area counted. Negative HER 2 status was considered as a score of between 0 and $1+$, using IHC, or a negative result upon fluorescence in situ hybridization (FISH).

FISH was performed using the PathVysion HER-2 DNA FISH kit, (Vysis, Inc.; Abbott Pharmaceutical) according to the manufacturer's instructions. Acid pretreatment and protease digestion were performed (Vysis paraffin pretreatment kit; Vysis, Inc.), followed by standard saline citrate (SSC) and formamide denaturation $\left(72^{\circ} \mathrm{C}\right.$ for $\left.5 \mathrm{~min}\right)$. After dehydration, the HER2/CEP 17 probe mixer was added. Slides 
were incubated in a moist chamber overnight at $37^{\circ} \mathrm{C}$ under a coverslip. On the following day, slides were washed in a stringency buffer (SSC, NP40), air-dried in the dark and incubated with 4,6 diamidino-2-phenylindole (DAPI) for nuclear identification.

21-gene RStesting. The tests were performed on formalin-fixed, paraffin-embedded tissues, as previously described $(10,25)$. In brief, fixed tissues were incubated for 5-10 h in 10\% neutral-buffered formalin prior to being alcohol-dehydrated and embedded in paraffin. Hematoxylin and eosin-stained slides were reviewed to assess the percentage of invasive breast cancer in the overall area. RNA was extracted from two $10-\mu \mathrm{m}$ unstained sections from sufficient (invasive component $\geq 50 \%$ ) invasive breast cancer with RNeasy FFPE Kit (cat. no. 73504; Qiagen, Inc.) according to the manufacturer's protocol. Total RNA content was measured, and the absence of DNA contamination was verified. Reverse transcription of the purified RNA was carried out with the Omniscript RT kit (Qiagen, Inc.) at $65^{\circ} \mathrm{C}$ for $5 \mathrm{~min}$ and $37^{\circ} \mathrm{C}$ for $60 \mathrm{~min}$. Probes for PCR were designed using Primer Express (Applied Biosystems; Thermo Fisher Scientific, Inc.) and Primer3 programs, as previously reported (26). The sequences of all probes are shown in Table SI. Gene-specific reverse transcription was performed followed by standardized quantitative PCR reactions in 96-well plates with TaqMan (DRR390A, Takara Biotechnology Co., Ltd.) using Applied Biosystems (Thermo Fisher Scientific, Inc.) 7500 Real-Time PCR system. The thermocycling conditions of the PCR were as follows: $95^{\circ} \mathrm{C}$ for $10 \mathrm{~min}, 95^{\circ} \mathrm{C}$ for $20 \mathrm{sec}$, and $60^{\circ} \mathrm{C}$ for $45 \mathrm{sec}$ (for 40 cycles). The expression of each gene was measured in triplicate and normalized relative to a set of 5 reference genes. The RS values, ranging between 0 and 100, were derived from the reference-normalized expression measurements of 16 cancer-associated genes (Ki-67, aurora kinase A, survivin (SURV), cyclin B1, MYB protooncogene-like 2, growth factor receptor bound protein 7 , HER2, ER, PR, B-cell lymphoma 2, Cub and EGF Like Domain Containing 2 protein, matrix metallopeptidase 11 , cathepsin $\mathrm{V}$, glutathione S-transferase $\mu 1$, cluster of differentiation 68 and BCL2-associated athanogene 1). These 16 cancer-related genes were selected as these were consistently univariately associated with clinical outcome in all three clinical association studies (27-29), and the selected five reference genes (actin $\beta$, GAPDH, glucuronidase $\beta$, ribosomal protein lateral stalk subunit P0 and transferrin receptor) consistently had a low variation in their expression and lacked any association with the clinical outcome in each clinical study (10). The expression levels of each gene were measured in triplicate. Patients were subsequently divided into low-risk ( $\mathrm{RS}<18)$, intermediate-risk (RS, 18-30) and high-risk ( $\mathrm{RS}>30)$ groups.

Adjuvant chemotherapy recommendation. Adjuvant treatment decisions for each patient with breast cancer were made by a multidisciplinary team comprising breast surgeons, medical oncologists, pathologists, radiation oncologists and specialized breast nurses. The recommended chemotherapy regimens included EC [epirubicin, $90 \mathrm{mg} / \mathrm{m}^{2}$ intravenously (IV) on day 1 ; and cyclophosphamide, $600 \mathrm{mg} / \mathrm{m}^{2} \mathrm{IV}$ on day 1 , every 21 days for 4 cycles], EC-T (epirubicin, $90 \mathrm{mg} / \mathrm{m}^{2} \mathrm{IV}$ on day 1 ; and cyclophosphamide, $600 \mathrm{mg} / \mathrm{m}^{2} \mathrm{IV}$ on day 1 , every 21 days for 4 cycles; followed by docetaxel, $80-100 \mathrm{mg} / \mathrm{m}^{2} \mathrm{IV}$ on day 1 , every 21 days for 4 cycles) and TC (docetaxel, $75 \mathrm{mg} / \mathrm{m}^{2}$ IV on day 1; and cyclophosphamide, $600 \mathrm{mg} / \mathrm{m}^{2}$ IV day 1 , every 21 days for 4 cycles).

Statistical analysis. The $\chi^{2}$ test was applied to evaluate the distribution of each RS risk category and chemotherapy recommendation among patients with different luminal subtypes and lymph node statuses. Fisher's exact test was performed when necessary (sample size $<40$ or minimum theoretical frequency $<5$ ). Logistic regression was used in the multivariate analyses to identify factors associated with chemotherapy recommendation. Expression of gene was measured in triplicate. Continuous variables were presented as mean \pm standard deviation. $\mathrm{P}<0.05$ was considered to indicate a statistically significant difference. Statistical analysis was performed using SPSS version 17.0 (SPSS, Inc.).

\section{Results}

Patients and baseline clinicopathological features. Between January 2014 and December 2016, 899 patients underwent 21-gene RS testing at Ruijin Hospital. A total of 772 patients with $\mathrm{HR}^{+} / \mathrm{HER} 2$ and $\mathrm{N}_{0-1}$ invasive ductal carcinoma for whom 21-gene RS testing results were available were included in the present study.

The baseline clinicopathological features of the patients are shown in Table I. Among the patients, 235 (30.44\%) were $<50$ years of age, $244(31.61 \%)$ had $\mathrm{T}_{2}$ tumors and $173(22.41 \%)$ were diagnosed with $\mathrm{N}_{1}$ tumors. A total of 254 cases (32.90\%) were classified as luminal A-like subtype and 518 (67.10\%) were classified as luminal B-like subtype. The mean value of RS in the whole population was $23.51 \pm 9.24$, with 184 patients (23.83\%) in the low risk RS category, 430 patients $(55.70 \%)$ in the intermediate risk RS category and 158 patients (20.47\%) in the high risk RS category (data not shown).

Association between clinicopathological features and adjuvant chemotherapy recommendation for the whole population. More than half of all patients (444/772 patients; $57.51 \%$ ) were recommended to receive adjuvant chemotherapy, which was the general recommendation for patients of younger age, premenopausal status, with less comorbidities, larger tumor size, lymph node involvement, higher tumor stage, higher tumor grade, low PR expression, high Ki-67 level, luminal B-like subtype and higher RS (all $\mathrm{P}<0.05$; Table I). In the multivariate analysis, lower CCI score, lymph node involvement, higher tumor grade, lower PR level, higher Ki-67 level and higher RS score were found to be independently associated with chemotherapy being recommended (Table II). Patients with high-risk RS were more likely to be recommended for chemotherapy, compared with those with low-risk RS [odds ratio (OR), 62.54; 95\% CI, 25.58-152.92; $\mathrm{P}<0.001$; Table II; Fig. 1].

When dividing RS into five intervals $(0-10,11-17,18-25$, 26-30 and $>30$ ), the proportion of patients for whom chemotherapy was recommended had the tendency to increase along with the 21-gene RS. For patients with an RS of 0-10 and 11-17, the proportion of patients that were not recommended for chemotherapy was 79.31 and $82.54 \%$, respectively, whereas only $50.15 \%$ of patients with a RS of $18-25$ did not receive 
Table I. Clinicopathological characteristics of patients and chemotherapy recommendation.

\begin{tabular}{|c|c|c|c|c|}
\hline \multirow[b]{2}{*}{ Variable } & \multirow[b]{2}{*}{ Patients, $\mathrm{n}$} & \multicolumn{2}{|c|}{ Chemotherapy recommendation } & \multirow[b]{2}{*}{ P-value } \\
\hline & & No chemotherapy, n (\%) & Chemotherapy, n (\%) & \\
\hline Age, years & & & & $<0.001$ \\
\hline$<50$ & 235 & $76(32.34)$ & 159 (67.66) & \\
\hline$\geq 50$ & 537 & $252(46.93)$ & $285(53.07)$ & \\
\hline Menopausal status & & & & $<0.001$ \\
\hline Premenopausal & 272 & $92(33.82)$ & $180(66.18)$ & \\
\hline Postmenopausal & 500 & $236(47.20)$ & $264(52.80)$ & \\
\hline Charlson comorbidity index & & & & $<0.001$ \\
\hline 0 & 204 & $65(31.86)$ & 139 (68.14) & \\
\hline $1-2$ & 328 & $112(34.15)$ & $216(65.85)$ & \\
\hline$\geq 3$ & 240 & $151(62.92)$ & $89(37.08)$ & \\
\hline Surgery & & & & 0.525 \\
\hline Mastectomy & 437 & $190(43.48)$ & $247(56.52)$ & \\
\hline BCS & 335 & $138(41.19)$ & $197(58.81)$ & \\
\hline T size stage & & & & $<0.001$ \\
\hline $\mathrm{T}_{1}$ & 528 & $255(48.30)$ & $273(51.70)$ & \\
\hline $\mathrm{T}_{2}$ & 244 & $73(29.92)$ & $171(70.08)$ & \\
\hline $\mathrm{N}$ stage & & & & $<0.001$ \\
\hline $\mathrm{N}_{0}$ & 599 & $302(50.42)$ & $297(49.58)$ & \\
\hline $\mathrm{N}_{1}$ & 173 & $26(15.03)$ & $147(84.97)$ & \\
\hline Stage & & & & $<0.001$ \\
\hline I & 461 & $243(52.71)$ & $218(47.29)$ & \\
\hline II-III & 311 & $85(27.33)$ & $226(72.67)$ & \\
\hline Grade & & & & $<0.001$ \\
\hline I & 96 & $71(73.96)$ & $25(26.04)$ & \\
\hline II & 489 & $230(47.03)$ & $259(52.97)$ & \\
\hline III & 187 & $27(14.44)$ & $160(85.56)$ & \\
\hline ER & & & & 0.102 \\
\hline$<50 \%$ & 26 & $7(26.92)$ & $19(73.08)$ & \\
\hline$\geq 50 \%$ & 746 & $321(43.03)$ & $425(56.97)$ & \\
\hline PR & & & & $<0.001$ \\
\hline$<20 \%$ & 261 & $69(26.44)$ & $192(73.564)$ & \\
\hline$\geq 20 \%$ & 511 & $259(50.68)$ & $252(49.32)$ & \\
\hline Ki-67 & & & & $<0.001$ \\
\hline$<14 \%$ & 378 & $229(60.58)$ & $149(39.42)$ & \\
\hline$\geq 14 \%$ & 394 & $99(25.13)$ & $295(74.87)$ & \\
\hline Subtypes & & & & $<0.001$ \\
\hline Luminal A-like & 254 & $176(69.29)$ & $78(30.71)$ & \\
\hline Luminal B-like & 518 & $152(29.34)$ & 366 (70.66) & \\
\hline RS categories & & & & $<0.001$ \\
\hline Low & 184 & 150 (81.52) & 34 (18.48) & \\
\hline Intermediate & 430 & $167(38.84)$ & $263(61.16)$ & \\
\hline High & 158 & $11 \quad(6.96)$ & 147 (93.04) & \\
\hline
\end{tabular}

$\chi^{2}$ test was applied to evaluate the association between chemotherapy recommendation and clinicopathological characteristics of patients BCS, breast-conserving surgery; T, tumor; N, node; ER, estrogen receptor; PR, progesterone receptor; RS, recurrence score.

a chemotherapy recommendation. The proportion of chemotherapy recommended patients further increased to $83.92 \%$ in
RS 26-30 patients, and to $93.04 \%$ in patients with an $\mathrm{RS}>30$ (Fig. S1). 
Table II. Multivariate analysis for factors influencing chemotherapy recommendation.

\begin{tabular}{|c|c|c|c|}
\hline Variables & OR & $95 \% \mathrm{CI}$ & P-value \\
\hline Age, years & & & 0.151 \\
\hline$\geq 50$ & 1.00 & & \\
\hline$<50$ & 2.22 & $0.75-6.59$ & \\
\hline Charlson comorbidity index & & & $<0.001$ \\
\hline 0 & 1.00 & & \\
\hline $1-2$ & 0.64 & $0.38-1.08$ & \\
\hline$\geq 3$ & 0.11 & $0.06-0.20$ & \\
\hline $\mathrm{T}$ size stage & & & 0.201 \\
\hline $\mathrm{T}_{1}$ & 1.00 & & \\
\hline $\mathrm{T}_{2}$ & 1.37 & $0.85-2.22$ & \\
\hline $\mathrm{N}$ stage & & & $<0.001$ \\
\hline $\mathrm{N}_{0}$ & 1.00 & & \\
\hline $\mathrm{N}_{1}$ & 16.09 & $8.49-30.50$ & \\
\hline Grade & & & $<0.001$ \\
\hline $\mathrm{I}$ & 1.00 & & \\
\hline II & 2.36 & $1.23-4.55$ & \\
\hline III & 7.48 & $3.13-17.90$ & \\
\hline ER & & & 0.574 \\
\hline$\geq 50 \%$ & 1.00 & & \\
\hline$<50 \%$ & 0.674 & $0.17-2.67$ & \\
\hline PR & & & $<0.001$ \\
\hline$\geq 20 \%$ & 1.00 & & \\
\hline$<20 \%$ & 2.99 & $1.81-4.92$ & \\
\hline Ki-67 & & & $<0.001$ \\
\hline$\leq 14 \%$ & 1.00 & & \\
\hline$>14 \%$ & 4.54 & $2.82-7.31$ & \\
\hline Subtypes & & & 0.172 \\
\hline Luminal A-like & 1.00 & & \\
\hline Luminal B-like & 1.94 & $0.75-5.01$ & \\
\hline RS categories & & & $<0.001$ \\
\hline Low & 1.00 & & \\
\hline Intermediate & 9.04 & $5.18-15.77$ & \\
\hline High & 62.54 & $25.58-152.92$ & \\
\hline
\end{tabular}

Factors associated with chemotherapy recommendation in the multivariate analyses were identified using logistic regression analysis. $\mathrm{T}$, tumor; N, node; ER, estrogen receptor; PR, progesterone receptor; RS, recurrence score; OR, odds ratio; CI, confidence interval.

There were 3 patients who received capecitabine alone, due to age and comorbidities. Among the 441 patients who received standard intravenous chemotherapy, the chemotherapy regimens and cycles recommended were associated with 21-gene RS. Among patients in the low RS category, $94.1 \%$ received fewer cycles of chemotherapy, and the regimens included either anthracycline or taxane. On the other hand, among patients in the high RS category, $36.8 \%$ received more cycles of chemotherapy, for which both anthracycline and taxane were used $(\mathrm{P}<0.001$; Table SII).

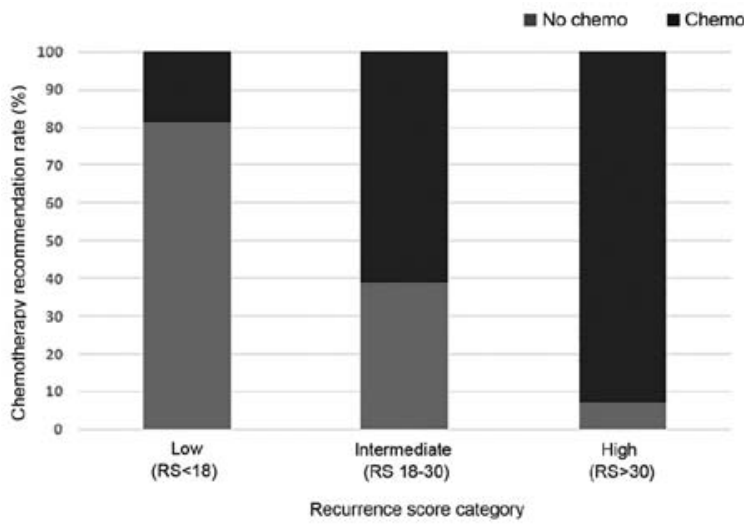

Figure 1. Chemotherapy recommendation according to RS categories in the whole population. RS, recurrence score; Chemo, chemotherapy.

Chemotherapy recommendation for patients with luminal A-like subtype breast cancer. A total of 254 patients with luminal A-like breast cancer were included in the present study. Based on the 21-gene RS test results, 35.83\% (91/254) of luminal A-like subtype patients were classified in the low RS category, $58.27 \%$ (148/254) in the intermediate RS category and $5.91 \%(15 / 254)$ in the high RS category (Table III). Chemotherapy was recommended for the majority of patients with a high RS (93.33\%), but was recommended for only $37.84 \%$ patients with an intermediate RS and $8.79 \%$ of patients with a low RS (Table III).

For patients with breast cancer of the luminal A-like subtype, chemotherapy was recommended for $30.71 \%(78 / 254)$. Clinicopathological factors, including age, CCI score, tumor size, lymph node status, tumor grade and RS category, were found to be associated with chemotherapy recommendation upon univariate analysis. In the multivariate analysis, chemotherapy recommendation was found to be associated with a younger age (OR, 5.98; 95\% CI, 1.04-34.99; $\mathrm{P}=0.046)$, lower CCI ( $\geq 3$ vs. 0 ; OR, $0.25 ; 95 \%$ CI, 0.03-2.08; $\mathrm{P}=0.019$ ), lymph node involvement (OR, 39.40; 95\% CI, 12.75-121.73; $\mathrm{P}<0.001)$, grade III (OR, 14.21; 95\% CI, 1.48-136.37; $\mathrm{P}=0.047)$ and the high-risk RS category (OR, 435.05; 95\% CI, 29.90-6331.06; $\mathrm{P}<0.001$ ) (Table III). Notably, the chemotherapy recommendation rate in the high-risk RS category was 10 times higher than that in the low risk RS category for patients with luminal A-like subtype breast cancer (Fig. 2).

Chemotherapy recommendation for patients with luminal B-like subtype breast cancer. Among the 518 patients with luminal B-like breast cancer, $17.95 \%$ were categorized as low RS, $54.44 \%$ as intermediate RS and $27.61 \%$ as high RS (Table IV). In the group of patients with luminal B-like subtype breast cancer, adjuvant chemotherapy was recommended for 93.01\% of patients in the high-risk RS category, whereas adjuvant chemotherapy was recommended for only $27.96 \%$ of patients in the low-risk RS category (Fig. 2). In addition to age, CCI score, tumor size, lymph node status, tumor grade and Ki-67 expression, RS was also associated with chemotherapy recommendation upon univariate analysis (Table IV). Belonging to the high-risk RS category was an important independent influencing factor for chemotherapy decision compared with belonging to the low risk RS category (OR, 57.20: 95\% CI, 22.42-145.96; $\mathrm{P}<0.001$ ). 
Table III. Clinicopathological features and chemotherapy recommendation in patients with luminal A-like subtype breast cancer.

\begin{tabular}{|c|c|c|c|c|c|c|}
\hline \multirow[b]{3}{*}{ Variables } & \multicolumn{3}{|c|}{ Univariate analysis } & \multirow{2}{*}{\multicolumn{3}{|c|}{ Multivariate analysis }} \\
\hline & \multirow{2}{*}{$\begin{array}{c}\text { No chemotherapy, } \\
n(\%)\end{array}$} & \multirow{2}{*}{$\begin{array}{c}\text { Chemotherapy, } \\
\text { n }(\%)\end{array}$} & \multirow[b]{2}{*}{ P-value } & & & \\
\hline & & & & OR & $95 \% \mathrm{CI}$ & P-value \\
\hline Age, years & & & $<0.001$ & & & 0.046 \\
\hline$\geq 50$ & $131(79.39)$ & $34(20.61)$ & & 1.00 & & \\
\hline$<50$ & $45(50.56)$ & $44(49.44)$ & & 5.98 & $1.04-34.99$ & \\
\hline Charlson comorbidity index & & & $<0.001$ & & & 0.019 \\
\hline 0 & $39(50.65)$ & $38(49.35)$ & & 1.00 & & \\
\hline $1-2$ & $67(68.37)$ & $31(31.63)$ & & 1.53 & $0.28-8.37$ & \\
\hline$\geq 3$ & $70(88.61)$ & $9(11.39)$ & & 0.25 & $0.03-2.08$ & \\
\hline $\mathrm{T}$ size stage & & & 0.036 & & & 0.422 \\
\hline $\mathrm{T}_{1}$ & $139(72.77)$ & $52(27.23)$ & & 1.00 & & \\
\hline $\mathrm{T}_{2}$ & $37(58.73)$ & $26(41.27)$ & & 1.46 & $0.58-3.70$ & \\
\hline $\mathrm{N}$ stage & & & $<0.001$ & & & $<0.001$ \\
\hline $\mathrm{N}_{0}$ & $160(80.00)$ & $40(20.00)$ & & 1.00 & & \\
\hline $\mathrm{N}_{1}$ & $16(29.63)$ & $38(70.37)$ & & 39.40 & $12.75-121.73$ & \\
\hline Grade & & & $<0.001$ & & & 0.047 \\
\hline I & $54(83.08)$ & $11(16.92)$ & & 1.00 & & \\
\hline II & $120(67.04)$ & $59(32.96)$ & & 2.49 & $0.88-7.03$ & \\
\hline III & $2(20.00)$ & $8(80.00)$ & & 14.21 & $1.48-136.37$ & \\
\hline ER & & & 0.555 & - & & 0.999 \\
\hline$\geq 50 \%$ & $173(68.92)$ & $78(31.08)$ & & & & \\
\hline$<50 \%$ & $3(100.00)$ & $\begin{array}{ll}0 & (0.00)\end{array}$ & & & & \\
\hline RS categories & & & $<0.001$ & & & $<0.001$ \\
\hline Low & $83(91.21)$ & $8 \quad(8.79)$ & & 1.00 & & \\
\hline Intermediate & $92(62.16)$ & $56(37.84)$ & & 7.93 & $2.64-23.83$ & \\
\hline High & 1 (6.67) & $14(93.33)$ & & 435.05 & $29.90-6331.06$ & \\
\hline
\end{tabular}

Association between chemotherapy recommendation and clinicopathological characteristics was evaluated using the $\chi^{2}$ test. Fisher's exact test was performed when total number of cases was $<40$ or minimum theoretical frequency was $<5$. Factors associated with chemotherapy recommendation in the multivariate analyses were identified using logistic regression. T, tumor; $\mathrm{N}$, node; ER, estrogen receptor; RS, recurrence score; OR, odds ratio; CI, confidence interval.

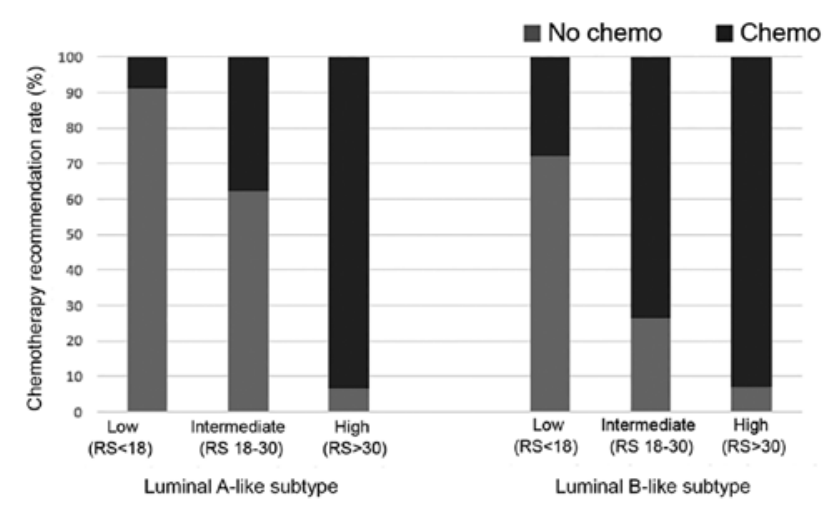

Figure 2. Chemotherapy recommendation according to RS categories stratified by luminal subtype. RS, recurrence score; Chemo, chemotherapy.

Chemotherapy recommendation for patients stratified by lymph node status. The association between clinicopathological features and chemotherapy recommendation stratified by lymph node status was further analyzed (Tables SIII and SIV). Among lymph node-negative patients, chemotherapy was recommended for $91.60 \%$ in the high-risk RS category, whereas the percentage rose to $97.44 \%$ for patients with node-positive breast cancer (Fig. S2). Lower CCI score, higher Ki-67 level and higher risk RS category were independent factors that influenced chemotherapy recommendation for both node-negative and node-positive patients according to multivariate analyses, whereas higher tumor grade and lower PR level were associated with chemotherapy recommendation only in node-negative patients (Tables SIII and SIV). The high risk RS category was found to be impact factor with highest $O R$ value for node-negative (OR, 84.04; 95\% CI, 31.11-227.05; $\mathrm{P}<0.001$ ) and node-positive patients (OR, 20.83; 95\% CI, 2.06-210.59; $\mathrm{P}=0.002)$.

Chemotherapy recommendation for patients with luminal A-like subtype breast cancer and a high RS or patients with luminal B-like subtype breast cancer and a low RS. A total of 15 patients with breast cancer with luminal A-like subtype 
Table IV. Clinicopathological features and chemotherapy recommendation in patients with luminal B-like subtype breast cancer.

\begin{tabular}{|c|c|c|c|c|c|c|}
\hline \multirow[b]{3}{*}{ Variables } & \multicolumn{3}{|c|}{ Univariate analysis } & \multirow{2}{*}{\multicolumn{3}{|c|}{ Multivariate analysis }} \\
\hline & \multirow{2}{*}{$\begin{array}{c}\text { No chemotherapy, } \\
n(\%)\end{array}$} & \multirow{2}{*}{$\begin{array}{c}\text { Chemotherapy, } \\
\mathrm{n}(\%)\end{array}$} & \multirow[b]{2}{*}{ P-value } & & & \\
\hline & & & & OR & $95 \% \mathrm{CI}$ & P-value \\
\hline Age, years & & & 0.011 & & & 0.979 \\
\hline$\geq 50$ & $121(32.53)$ & $251(67.47)$ & & 1.00 & & \\
\hline$<50$ & $31(21.23)$ & $115(78.77)$ & & 1.02 & $0.25-4.22$ & \\
\hline Charlson comorbidity index & & & $<0.001$ & & & $<0.001$ \\
\hline 0 & $26(20.47)$ & $101(79.53)$ & & 1.00 & & \\
\hline $1-2$ & 45 (19.57) & $185(80.43)$ & & 1.00 & $0.50-1.99$ & \\
\hline$\geq 3$ & $81(50.31)$ & $80(49.69)$ & & 0.17 & $0.08-0.35$ & \\
\hline T stage & & & 0.001 & & & 0.281 \\
\hline $\mathrm{T}_{1}$ & $116(34.42)$ & $221(65.58)$ & & 1.00 & & \\
\hline $\mathrm{T}_{2}$ & $36(19.89)$ & $145(80.11)$ & & 1.38 & $0.77-2.45$ & \\
\hline $\mathrm{N}$ stage & & & $<0.001$ & & & $<0.001$ \\
\hline $\mathrm{N}_{0}$ & $142(35.59)$ & $257(64.41)$ & & 1.00 & & \\
\hline $\mathrm{N}_{1}$ & $10(8.40)$ & $109(91.60)$ & & 10.60 & $4.59-24.51$ & \\
\hline Grade & & & $<0.001$ & & & 0.001 \\
\hline I & $17(54.84)$ & $14(45.16)$ & & 1.00 & & \\
\hline II & $110(35.48)$ & $200(64.52)$ & & 2.42 & $0.95-6.17$ & \\
\hline III & $25(14.12)$ & $152(85.88)$ & & 6.80 & $2.28-20.27$ & \\
\hline ER & & & 0.198 & & & 0.859 \\
\hline$\geq 50 \%$ & $148(29.90)$ & $347(70.10)$ & & 1.00 & & \\
\hline$<50 \%$ & $4(17.39)$ & $19(82.61)$ & & 1.16 & $0.23-5.70$ & \\
\hline PR & & & 0.143 & & & 0.112 \\
\hline$\geq 20 \%$ & 83 (32.30) & $174(67.70)$ & & 1.00 & & \\
\hline$<20 \%$ & 69 (26.44) & $192(73.56)$ & & 1.87 & $0.87-4.03$ & \\
\hline Ki-67 & & & $<0.001$ & & & 0.031 \\
\hline$\leq 14 \%$ & $53(42.74)$ & $71(57.26)$ & & 1.00 & & \\
\hline$>14 \%$ & 99 (25.13) & 295 (74.87) & & 1.94 & $1.06-3.53$ & \\
\hline RS categories & & & $<0.001$ & & & $<0.001$ \\
\hline Low & 67 (72.04) & $26(27.96)$ & & 1.00 & & \\
\hline Intermediate & 75 (26.60) & $207(73.40)$ & & 11.77 & $6.10-22.72$ & \\
\hline High & $10(6.99)$ & $133(93.01)$ & & 57.20 & $22.42-145.96$ & \\
\hline
\end{tabular}

Association chemotherapy recommendation and clinicopathological characteristics were evaluated using the $\chi^{2}$ test. Factors associated with chemotherapy recommendation in the multivariate analyses were identified using logistic regression. $\mathrm{T}$, tumor; $\mathrm{N}$, node; ER, estrogen receptor; $\mathrm{PR}$, progesterone receptor; $\mathrm{RS}$, recurrence score; OR, odds ratio; CI, confidence interval.

tumors were identified to have a high RS (5.91\%), whereas 93 patients with the luminal B-like subtype were identified to have a low RS (17.95\%). Chemotherapy was recommended for 93.33\% (14/15) of patients with luminal A-like subtype breast cancer and a high RS, and for $27.96 \%$ (26/93) of patients with luminal B-like subtype breast cancer and a low RS. For these 108 patients, age $(\mathrm{P}=0.026)$, CCI score $(\mathrm{P}=0.003)$, lymph node status $(\mathrm{P}<0.001)$, luminal subtypes $(\mathrm{P}<0.001)$ and RS category $(\mathrm{P}<0.001)$ were associated with chemotherapy decision according to the univariate analysis (Table V). In the multivariate analysis, lymph node involvement (OR, 55.04; 95\% CI, 9.07-333.89; $\mathrm{P}<0.001$ ), lower CCI ( $\geq 3$ vs. 0; OR, 0.90; $95 \% \mathrm{CI}, 0.05-16.43 ; \mathrm{P}=0.034)$ and the high $\mathrm{RS}$ category
(OR, 134.52; 95\% CI, 10.39-1741.89; $\mathrm{P}<0.001)$ were found to be independently associated with chemotherapy recommendation (Table VI).

\section{Discussion}

The present study assessed the influence of the 21-gene RS on chemotherapy decision for patients with $\mathrm{HR}^{+} / \mathrm{HER}^{-}$breast cancer of different luminal subtypes. The present study revealed that the 21-gene RS was independently associated with adjuvant chemotherapy recommendation in patients with breast cancer, regardless of their luminal subtype and lymph node status. For patients with luminal A-like subtype breast 
Table V. Chemotherapy recommendation in patients with breast cancer with luminal A-like subtype and low RS or luminal B-like subtype and high RS tumors.

\begin{tabular}{|c|c|c|c|c|}
\hline Variables & Patients, $\mathrm{n}$ & No chemotherapy, n (\%) & Chemotherapy, n (\%) & P-value \\
\hline Age, years & & & & 0.026 \\
\hline$\geq 50$ & 71 & $50 \quad(70.42)$ & $21(29.58)$ & \\
\hline$<50$ & 37 & $18(48.65)$ & $19(51.35)$ & \\
\hline Charlson comorbidity index & & & & 0.003 \\
\hline 0 & 30 & $16 \quad(53.33)$ & $14(46.67)$ & \\
\hline $1-2$ & 37 & 18 (48.65) & $19(51.35)$ & \\
\hline$\geq 3$ & 41 & $34 \quad(82.93)$ & 7 (17.07) & \\
\hline T size stage & & & & 0.961 \\
\hline $\mathrm{T}_{1}$ & 78 & 49 (62.82) & $29(37.18)$ & \\
\hline $\mathrm{T}_{2}$ & 30 & $19(63.33)$ & $11(36.67)$ & \\
\hline $\mathrm{N}$ stage & & & & $<0.001$ \\
\hline $\mathrm{N}_{0}$ & 88 & $64 \quad(72.73)$ & $24(27.27)$ & \\
\hline $\mathrm{N}_{1}$ & 20 & $4(20.00)$ & $16(80.00)$ & \\
\hline Grade & & & & 0.078 \\
\hline $\mathrm{I}$ & 8 & $6(75.00)$ & $2(25.00)$ & \\
\hline II & 73 & $50 \quad(68.49)$ & $23(31.51)$ & \\
\hline III & 27 & 12 (44.44) & $15(55.56)$ & \\
\hline ER & & & & 0.529 \\
\hline$\geq 50 \%$ & 106 & 66 (62.26) & $40(37.74)$ & \\
\hline$<50 \%$ & 2 & $2(100.00)$ & $0 \quad(0.00)$ & \\
\hline Subtypes & & & & $<0.001$ \\
\hline Luminal A-like & 15 & $1(6.67)$ & $14(93.33)$ & \\
\hline Luminal B-like & 93 & $67(72.04)$ & $26(27.96)$ & \\
\hline RS categories & & & & $<0.001$ \\
\hline Low & 93 & $67(72.04)$ & $26(27.96)$ & \\
\hline High & 15 & $1(6.67)$ & $14(93.33)$ & \\
\hline
\end{tabular}

Association between chemotherapy recommendations and clinicopathological characteristics was evaluated using the $\chi^{2}$ test. Fisher's exact test was performed when total number of cases was $<40$ or minimum theoretical frequency was $<5$. T, tumor; N, node; ER, estrogen receptor; RS, recurrence score.

cancer with a high RS or luminal B-like subtype with a low $\mathrm{RS}$, high RS was identified to be the most important factor influencing adjuvant chemotherapy decision when compared with low RS (adjusted OR, 134.52).

Currently, two methods are used to determine breast cancer subtypes: Multigene-based assays and IHC-based markers. Based on a previous study conducted by Prat et al (30), the definition of the luminal A-like subtype was updated as ER-positive, PR $\geq 20 \%$, HER2-negative and Ki-67 <14\% (21). Additionally, the 2013 St. Gallen expert consensus added a 'recurrence risk of 'low' based on multi-gene-expression assay (if available)' to the definition of the luminal A-like subtype (21). In clinical trials $(8,9,13)$, chemotherapy has been assigned strictly based on the study design. For example, in a prospective clinical trial of TAILORx for the 21-gene $\mathrm{RS}$, patients with a score of 0-10 were assigned to receive endocrine therapy alone, and those with a score $\geq 26$ were assigned to receive chemotherapy plus endocrine therapy (8). However, in the real world, treatment decisions are usually developed based on a comprehensive consideration of all types of clinicopathological characteristics. In the present study, adjuvant treatment decisions for each patient with breast cancer were made by a multidisciplinary team that took all-sided patient characteristics into consideration, which may help assess the associations among clinicopathological features, the 21-gene $\mathrm{RS}$ and chemotherapy recommendation for $\mathrm{HR}^{+} / \mathrm{HER} 2^{-}$ patients.

The cutoff points were pre-specified prior to the validation study of the RS (10), which categorized patients into low-risk ( $\mathrm{RS}<18$ ), intermediate-risk ( $\mathrm{RS} \geq 18$ and $<31$ ) and high-risk ( $\mathrm{RS} \geq 31$ ) groups. Low-risk patients have a good prognosis and benefit little from additional chemotherapy, whereas for high-risk patients, chemotherapy is highly recommended. This cutoff point has been widely used in subsequent validation studies of the 21-gene RS $(11,12,17)$. The aforementioned cutoff points were also pre-specified in the present study. Since the prospective clinical trials for the 21-gene RS used different cutoff values, including $\mathrm{RS}<11$ ( $\leq 11$ in Plan B 
Table VI. Multivariate analysis of chemotherapy decision influencing factors in patients with luminal A-like subtype and low RS or luminal B-like subtype and high RS tumors.

\begin{tabular}{|c|c|c|c|}
\hline Variables & OR & $95 \% \mathrm{CI}$ & P-value \\
\hline Age, years & & & 0.096 \\
\hline$\geq 50$ & 1.00 & & \\
\hline$<50$ & 9.56 & $0.67-136.85$ & \\
\hline $\begin{array}{l}\text { Charlson comorbidity } \\
\text { index }\end{array}$ & & & 0.034 \\
\hline 0 & 1.00 & & \\
\hline $1-2$ & 6.09 & $0.44-84.95$ & \\
\hline$\geq 3$ & 0.90 & $0.05-16.43$ & \\
\hline $\mathrm{N}$ stage & & & $<0.001$ \\
\hline $\mathrm{N}_{0}$ & 1.00 & & \\
\hline $\mathrm{N}_{1}$ & 55.04 & $9.07-333.89$ & \\
\hline Grade & & & 0.005 \\
\hline $\mathrm{I}$ & 1.00 & & \\
\hline II & 1.78 & $0.08-41.90$ & \\
\hline III & 20.78 & $0.81-531.84$ & \\
\hline RS categories & & & $<0.001$ \\
\hline Low & 1.00 & & \\
\hline High & 134.52 & $10.39-1741.89$ & \\
\hline
\end{tabular}

Factors associated with chemotherapy recommendation in the multivariate analyses were identified using logistic regression. T, tumor; $\mathrm{N}$, node; RS, recurrence score; $\mathrm{OR}$, odds ratio; $\mathrm{CI}$, confidence interval.

study), 11-25 and RS $>25$, the present study also analyzed the change in the chemotherapy recommended along with 21-gene RS intervals. The results revealed that a similar proportion of patients with RS 0-10 and 11-17 were spared from chemotherapy (79.31 and $82.54 \%$ ), whereas RS 26-30 and $\mathrm{RS}>30$ patients had a high proportion of chemotherapy recommendation (83.92 and 93.04\%).

The recommendation of multi-gene profiles for clinically low-risk patients may have certain challenges. The 70-gene prognosis signature has limited value in $\mathrm{HR}^{+} / \mathrm{HER} 2$, node-negative patients with low clinical risk, since these patients have excellent outcomes even with a genomic high-risk cancer and omitting chemotherapy $(19,31)$. However, to the best of our knowledge, there is a lack of data regarding the role of the 21-gene RS in low clinical risk patients, including patients with luminal A disease. In the present study, a total of 15 patients with luminal A-like subtype breast cancer were classified as high RS (5.91\%). Despite the small percentage of high RS patients with luminal A-like subtype breast cancer, 93.3\% of them were recommended to receive adjuvant chemotherapy. In addition, the high RS category was revealed to be the most influential factor for chemotherapy recommendation in patients with luminal A-like breast cancer (OR, 435.05; $\mathrm{P}<0.001)$.

Although the 2013 St. Gallen Consensus recommends the usage of multigene signatures, particularly in luminal B disease, for the selection of patients who should receive adjuvant chemotherapy (21), few studies have focused on the role of the 21-gene RS in luminal B breast cancer $(32,33)$. In the prospective Plan B study, $12 \%$ of luminal B (Ki-67 $\geq 20 \%$ ) tumors were found to be of low risk $(\mathrm{RS} \leq 11)$ and $48 \%$ were found to be of intermediate risk (RS, 12-25) according to the 21-gene RS (34). Similarly, in the present study, $17.95 \%$ of luminal B-like tumors were identified to be of low risk (RS <18) and $54.44 \%$ were identified to be of intermediate risk (RS, 18-30). Additionally, $72.04 \%$ of low-risk RS patients with luminal B-like subtype breast cancer were not recommended to receive adjuvant chemotherapy, which indicated that physicians are more confident using the 21-gene RS score to guide adjuvant chemotherapy decisions rather than routine clinicopathological features.

Evidence for the utility value of the 21-gene RS in node-positive disease is mostly derived from retrospective analysis, making it less robust than that in the node-negative population. As a result, recommendations of major cancer associations currently differ, with the American Society of Clinical Oncology recommending the 21-gene RS for node-negative patients only, whereas the NCCN recommends the 21-gene RS for patients with limited node positivity (1-3 involved nodes) (14,31). However, the 21 -gene RS remains one of the few multigene assays that have been validated for prediction of the likelihood of chemotherapy benefit for node-positive patients (12). Additionally, in the transATAC study, node-positive patients with a low RS exhibited good prognosis without receiving chemotherapy (the rate of disease recurrence at 9 years was $17 \%$ for RS <18) (17). In the Plan B study, disease-free survival in $\mathrm{pN}_{1}$ patients with low RS reached $97 \%$ without chemotherapy $(97.9 \%$ for $\mathrm{RS}<12$ and $97.2 \%$ for RS 12-25), which is similar to that of $\mathrm{pN}_{0}$ patients (98.6\% for $\mathrm{RS}<12$ and $98.5 \%$ for $\mathrm{RS} 12-25$ ) (9). In the present study, $39.3 \%$ of node-positive patients with a low RS were not recommended to receive chemotherapy. After adjusting for clinicopathological factors, the 21-gene RS was found to be the most important impact factor for chemotherapy recommendation for node-positive patients (OR, 20.83; $\mathrm{P}=0.002$ ).

In a clinical setting, patients may be classified into different risk groups based on clinicopathological characteristics and genomic assays. In the MINDACT clinical trial, $8.85 \%(592 / 6,693)$ of patients were of a low clinical risk and high genomic risk, whereas $23.16 \%(1,550 / 6,693)$ of patients were of a high clinical risk and low genomic risk (19). The results show that patients with high clinical risk and low genomic risk receive little benefit from additional chemotherapy (19). However, to the best of our knowledge, for patients with a discordant risk of the 21-gene RS and clinicopathological characteristics, including luminal subtypes, there is no solid evidence to guide the treatment decision. In the present study, 5.91\% (15/254) of patients with luminal A-like breast cancer were categorized as high RS, while chemotherapy was recommended for $93.33 \%$ of them; whereas $17.95 \%(93 / 518)$ of patients with luminal B-like breast cancer were categorized as low RS, and chemotherapy was recommended for only $27.96 \%$ of them. Multivariate analyses demonstrated that the 21-gene RS is the most important impact factor for chemotherapy recommendation for all patients, regardless of luminal subtype or node status, with an adjusted OR of 62.54 $(\mathrm{P}<0.001)$. 
The present study has several limitations. First, it is a retrospective study. Patients were from a single-center and enrollment bias may exist. Second, some $\mathrm{N}_{1}$ patients were included. The prognostic and predictive value of the 21-gene RS for node-positive patients was not validated through prospective clinical trials (12). The updated ASCO guidelines state that the 70 -gene prognosis signature can be applied to $\mathrm{HR}^{+} / \mathrm{HER} 2-$ patients with one positive node, but not to those with 2-3 positive nodes. Third, various clinicopathological characteristics were taken into consideration when the multidisciplinary team developed the treatment decision, but some of these, including patient performance status and comorbidities, were not discussed in the present study. Additionally, it should be noted that in the present study, IHC-based markers were used to determine breast cancer subtypes rather than PAM50 multigene-based assays. Finally, there was no long-term follow-up data in the study in order to analyze whether chemotherapy can improve disease outcome for these luminal subtypes and RS discordant cases. The findings may not be generalized at present, since further research and studies have to be conducted to reduce the limitations previously mentioned.

In conclusion, the present study demonstrated that the luminal subtypes and 21-gene RS are associated with chemotherapy recommendation for patients with $\mathrm{HR}^{+} / \mathrm{HER}^{-}$breast cancer. The RS was found to be independently associated with adjuvant chemotherapy recommendation in patients with breast cancer, regardless of luminal subtype and lymph node status. For patients of the luminal A-like subtype with a high RS or patients with luminal B-like subtype breast cancer with a low RS, a high RS is the most important independent factor that has an influence on the adjuvant chemotherapy decision.

\section{Acknowledgements}

The authors would like to thank Ms Yidong Du (Comprehensive Breast Health Center, Ruijin Hospital, Shanghai Jiaotong University School of Medicine) for assisting with data entry and Dr Yiwei Tong (Comprehensive Breast Health Center, Ruijin Hospital, Shanghai Jiaotong University School of Medicine) for assisting with language editing.

\section{Funding}

The present study was supported by the National Natural Science Foundation of China (grant no. 81772797).

\section{Availability of data and materials}

The datasets used and/or analyzed during the current study are available from the corresponding author on reasonable request.

\section{Authors' contributions}

$\mathrm{XC}$ and $\mathrm{KS}$ designed and conceived the study. WW, LL and XF performed the investigation. JH, WG, SZ, JW, OH, $\mathrm{JH}, \mathrm{YL}, \mathrm{LZ}$ and WC acquired the clinical data of patients. WW wrote the manuscript. XC and KS reviewed and edited the manuscript, and provided funds. All authors read and approved the manuscript and agree to be accountable for all aspects of the research in ensuring that the accuracy or integrity of any part of the work are appropriately investigated and resolved.

\section{Ethics approval and consent to participate}

The present study has been approved by the Ethic Committees of Shanghai Ruijin Hospital. All procedures performed involving human participants were in accordance with the ethical standards of the institutional committee and with the 1964 Helsinki Declaration and its later amendments or comparable ethical standards. Informed consent was obtained from all individual participants included in the study.

\section{Patient consent for publication}

Not applicable.

\section{Competing interests}

The authors declare that they have no competing interests.

\section{References}

1. Zheng RS, Sun KX, Zhang SW, Zeng HM, Zou XN, Chen R, $\mathrm{Gu} X Y$, Wei WW and He J: Report of cancer epidemiology in China, 2015. Zhonghua Zhong Liu Za Zhi 41: 19-28, 2019 (In Chinese; Abstract available in Chinese from the publisher).

2. Early Breast Cancer Trialists' Collaborative Group (EBCTCG): Effects of chemotherapy and hormonal therapy for early breast cancer on recurrence and 15-year survival: An overview of randomized trials. Lancet 365: 1687-1717, 2005.

3. Silberholz J, Bertsimas D and Vahdat L: Clinical benefit, toxicity and cost of metastatic breast cancer therapies: Systematic review and meta-analysis. Breast Cancer Res Treat 176: 535-543, 2019.

4. Alarid-Escudero F, Blaes AH and Kuntz KM: Trade-offs between efficacy and cardiac toxicity of adjuvant chemotherapy in early-stage breast cancer patients: Do competing risks matter? Breast J 23: 401-409, 2017.

5. De Abreu FB, Schwartz GN, Wells WA and Tsongalis GJ: Personalized therapy for breast cancer. Clin Genet 86: 62-67, 2014.

6. Coates AS, Winer EP, Goldhirsch A, Gelber RD, Gnant M, Piccart-Gebhart M, Thürlimann B and Senn HJ; Panel Members: Tailoring therapies-Improving the management of early breast cancer: St gallen international expert consensus on the primary therapy of early breast cancer 2015. Ann Oncol 26: 1533-1546, 2015.

7. Goldhirsch A, Wood WC, Coates AS, Gelber RD, Thürlimann B and Senn HJ; Panel members: Strategies for subtypes-dealing with the diversity of breast cancer: Highlights of the st gallen international expert consensus on the primary therapy of early breast cancer 2011. Ann Oncol 22: 1736-1747, 2011.

8. Sparano JA, Gray RJ, Makower DF, Pritchard KI, Albain KS, Hayes DF, Geyer CE Jr, Dees EC, Perez EA, Olson JA Jr, et al: Prospective validation of a 21-gene expression assay in breast cancer. N Engl J Med 373: 2005-2014, 2015.

9. Gluz O, Nitz UA, Christgen M, Kates RE, Shak S, Clemens M, Kraemer S, Aktas B, Kuemmel S, Reimer T, et al: West German Study Group Phase III PlanB trial: First prospective outcome data for the 21-gene recurrence score assay and concordance of prognostic markers by central and local pathology assessment. J Clin Oncol 34: 2341-2349, 2016.

10. Paik S, Shak S, Tang G, Kim C, Baker J, Cronin M, Baehner FL, Walker MG, Watson D, Park T, et al: A multigene assay to predict recurrence of tamoxifen-treated, node-negative breast cancer. N Engl J Med 351: 2817-2826, 2004

11. Paik S, Tang G, Shak S, Kim C, Baker J, Kim W, Cronin M, Baehner FL, Watson D, Bryant J, et al: Gene expression and benefit of chemotherapy in women with node-negative, estrogen receptor-positive breast cancer. J Clin Oncol 24: 3726-3734, 2006. 
12. Albain KS, Barlow WE, Shak S, Hortobagyi GN, Livingston RB Yeh IT, Ravdin P, Bugarini R, Baehner FL, Davidson NE, et al: Prognostic and predictive value of the 21-gene recurrence score assay in postmenopausal women with node-positive, oestrogen-receptor-positive breast cancer on chemotherapy: A retrospective analysis of a randomised trial. Lancet Oncol 11: 55-65, 2010.

13. Sparano JA, Gray RJ, Makower DF, Pritchard KI, Albain KS, Hayes DF, Geyer CE Jr, Dees EC, Goetz MP, Olson JA Jr, et al: Adjuvant chemotherapy guided by a 21-gene expression assay in breast cancer. N Engl J Med 379: 111-121, 2018.

14. Network NCC. NCCN Clinical Practice Guidlines in Oncology: Breast Cancer. Version 2.2017. at: http://www.ncen. org/professionals/physician_gls/pdf/breast_blocks.pdf. Accessed April 6, 2017.

15. Hornberger J, Alvarado MD, Rebecca C, Gutierrez HR, Yu TM and Gradishar WJ: Clinical validity/utility, change in practice patterns, and economic implications of risk stratifiers to predict outcomes for early-stage breast cancer: A systematic review. J Natl Cancer Inst 104: 1068-1079, 2012.

16. Habel LA, Shak S, Jacobs MK, Capra A, Alexander C, Pho M, Baker J, Walker M, Watson D, Hackett J, et al: A population-based study of tumor gene expression and risk of breast cancer death among lymph node-negative patients. Breast Cancer Res 8: R25, 2006.

17. Dowsett M, Cuzick J, Wale C, Forbes J, Mallon EA, Salter J, Quinn E, Dunbier A, Baum M, Buzdar A, et al: Prediction of risk of distant recurrence using the 21-gene recurrence score in node-negative and node-positive postmenopausal patients with breast cancer treated with anastrozole or tamoxifen: A TransATAC study. J Clin Oncol 28: 1829-1834, 2010.

18. Toi M, Iwata H, Yamanaka T, Masuda N, Ohno S, Nakamura S, Nakayama T, Kashiwaba M, Kamigaki S and Kuroi K; Japan Breast Cancer Research Group-Translational Research Group: Clinical significance of the 21-gene signature (Oncotype DX) in hormone receptor-positive early stage primary breast cancer in the Japanese population. Cancer 116: 3112-3118, 2010.

19. Van der Hoeven JJ: 70-Gene signature as an aid to treatment decisions in early-stage breast cancer. Ned Tijdschr Geneeskd 161: D1369, 2017 (In Dutch).

20. Charlson ME, Pompei P, Ales KL and MacKenzie CR: A new method of classifying prognostic comorbidity in longitudinal studies: Development and validation. J Chronic Dis 40: 373-383, 1987.

21. Goldhirsch A, Winer EP, Coates AS, Gelber RD, PiccartGebhart M, Thürlimann B and Senn HJ; Panel members: Personalizing the treatment of women with early breast cancer: Highlights of the st gallen international expert consensus on the primary therapy of early breast cancer 2013. Ann Oncol 24: 2206-2223, 2013.

22. Lakhani SR, Ellis IO, Schnitt SJ, Tan PH and van de Vijver MJ: WHO classification of tumours of the breast. In: World Health Organization Classification of Tumours. 4th edition. International Agency for Research on Cancer, Lyon, pp60-61, 2012.

23. Edge S, Byrd D and Compton C: AJCC Cancer Staging Handbook. 7th edition. American Joint Committee on Cancer, Springer, New York, NY, 2010.
24. Elston CW and Ellis IO: Pathological prognostic factors in breast cancer. I. The value of histological grade in breast cancer: Experience from a large study with long-term follow-up. Histopathology 19: 403-410, 1991.

25. Wu J, Fang Y, Lin L, Fei X, Gao W, Zhu S, Zong Y, Chen X, Huang $\mathrm{O}, \mathrm{He} \mathrm{J}$, et al: Distribution patterns of 21-gene recurrence score in 980 Chinese estrogen receptor-positive, HER2-negative early breast cancer patients. Oncotarget 8: 38706-38716, 2017.

26. Cronin M, Sangli C, Liu ML, Pho M, Dutta D, Nguyen A, Jeong J, Wu J, Langone KC and Watson D: Analytical validation of the Oncotype DX genomic diagnostic test for recurrence prognosis and therapeutic response prediction in node-negative, estrogen receptor-positive breast cancer. Clin Chem 53: 1084-1091, 2007.

27. Esteban J, Baker J, Cronin M, et al: Tumor gene expression and prognosis in breast cancer: Multi-gene RT-PCR assay of paraffin-embedded tissue. Proc Am Soc Clin Oncol 22: 850, 2003.

28. Paik S, Shak S, Tang G, et al: Multi-gene RT-PCR assay for predicting recurrence in node negative breast cancer patients: NSABP studies B-20 and B-14. Breast Cancer Res Treat 82: A16, 2003.

29. Cobleigh MA, Bitterman P, Baker J, et al: Tumor gene expression predicts distant disease-free survival (DDFS) in breast cancer patients with 10 or more positive nodes: High throughout RT-PCR assay of paraffin-embedded tumor tissues. Prog Proc Am Soc Clin Oncol 22: 850, 2003.

30. Prat A, Cheang MC, Martín M,Parker JS,Carrasco E, Caballero R, Tyldesley S, Gelmon K, Bernard PS, Nielsen TO and Perou CM: Prognostic significance of progesterone receptor-positive tumor cells within immunohistochemically defined luminal A breast cancer. J Clin Oncol 31: 203-209, 2013.

31. Harris LN, Ismaila N, McShane LM, Andre F, Collyar DE, Gonzalez-Angulo AM, Hammond EH, Kuderer NM, Liu MC, Mennel RG, et al: Use of biomarkers to guide decisions on adjuvant systemic therapy for women with early-stage invasive breast cancer: American Society of Clinical Oncology Clinical Practice Guideline. J Clin Oncol 34: 1134-1150, 2016.

32. Arima N, Nishimura R, Osako T, Okumura Y, Nakano M, Fujisue M, Nishiyama Y and Toyozumi Y: Ki-67 index value and progesterone receptor status can predict prognosis and suitable treatment in node-negative breast cancer patients with estrogen receptor-positive and HER2-negative tumors. Oncol Lett 17: 616-622, 2019.

33. Zhu L, Ma N, Wang B, Zhou C, Yan Y, Wang K, He J and Ren Y: Clinical analysis of 21-gene recurrence score test in hormone receptor-positive early-stage breast cancer. Oncol Lett 17: 5469-5480, 2019.

34. Nitz U, Gluz O, Christgen M, Kates RE, Clemens M, Malter W, Nuding B, Aktas B, Kuemmel S, Reimer T, et al: Reducing chemotherapy use in clinically high-risk, genomically low-risk pN0 and pN1 early breast cancer patients: Five-year data from the prospective, randomised phase 3 West German Study Group (WSG) PlanB trial. Breast Cancer Res Treat 165: 573-583, 2017. 